\title{
W-band ARM Cloud Radar Handbook
}

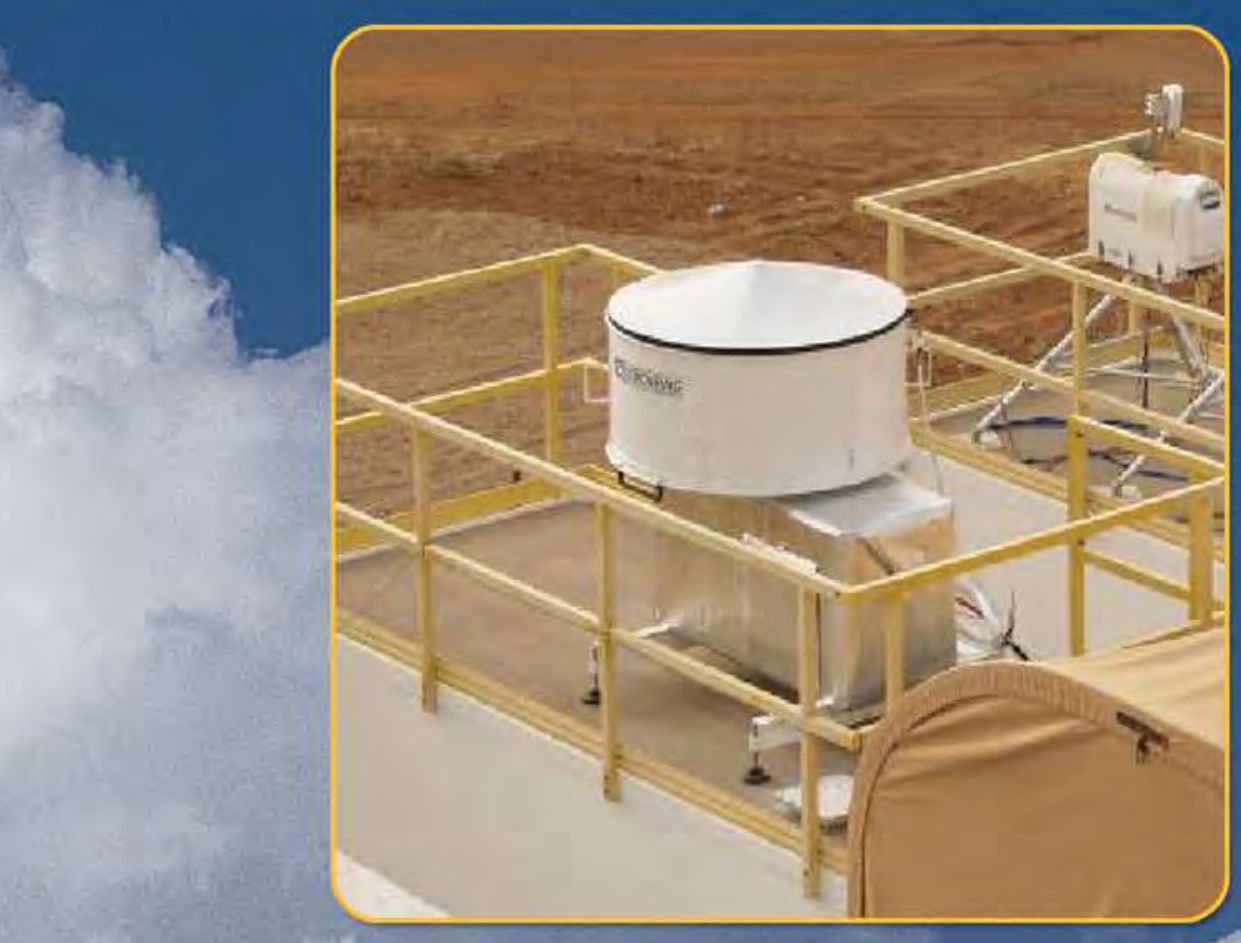

April 2006

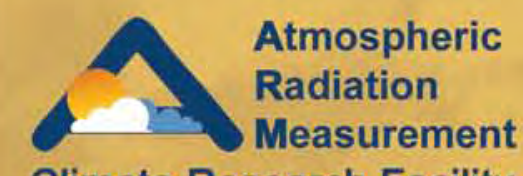

Climate Research Facility

U.S. Department of Energy

Work supported by the U.S. Department of Energy Office of Science, Office of Biological and Environmental Research 


\section{W-band ARM Cloud Radar (WACR) Handbook}

April 2006

K. B. Widener

K. Johnson

Work supported by the U.S. Department of Energy, Office of Science, Office of Biological and Environmental Research 


\section{Contents}

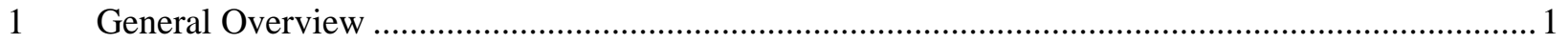

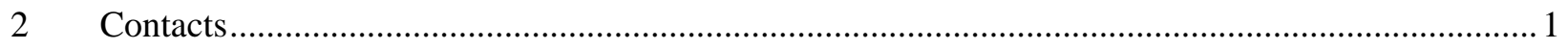

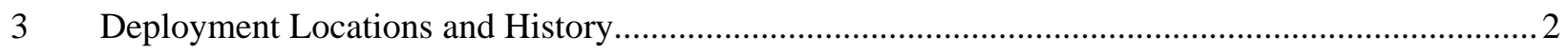

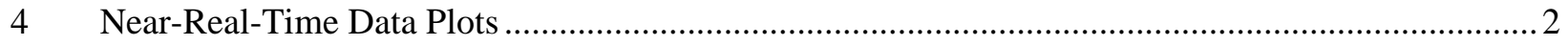

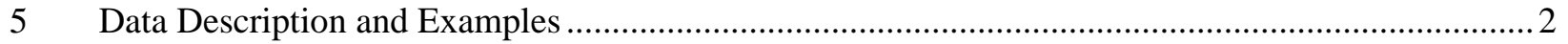

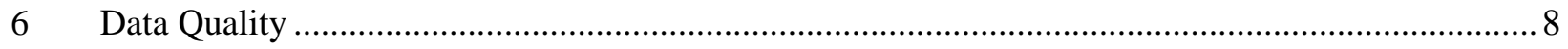

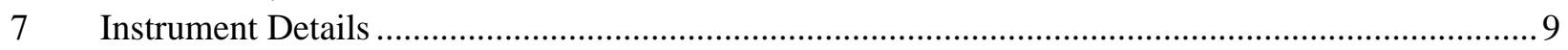

Figures

1 Plots of copolarization and cross-polarization moments, both for the SGP WACR .......................6

2 Plots of copolarization and cross-polarization moments from the AMF WACR at Niamey.............. 7

\section{Tables}

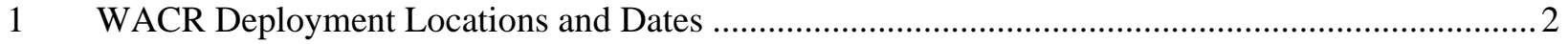

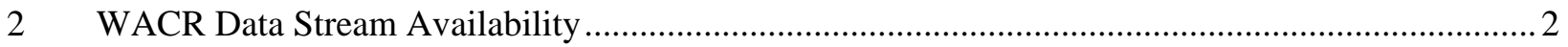

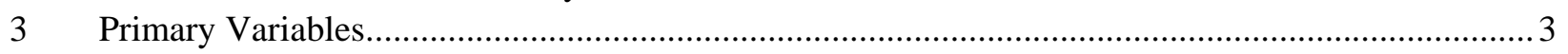

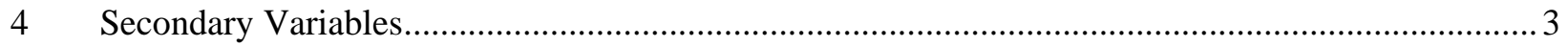

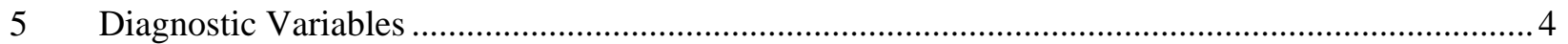

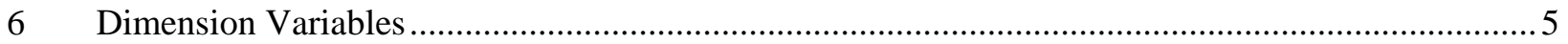

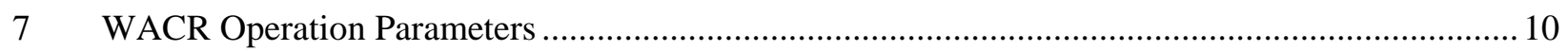




\section{General Overview}

The W-band Atmospheric Radiation Measurement (ARM) Program Cloud Radar (WACR) systems are zenith pointing Doppler radars that probe the extent and composition of clouds at $95.04 \mathrm{GHz}$. The main purpose of this radar is to determine cloud boundaries (e.g., cloud bottoms and tops). This radar reports estimates for the first three spectra moments for each range gate up to $15 \mathrm{~km}$. The $0^{\text {th }}$ moment is reflectivity, the $1^{\text {st }}$ moment is radial velocity, and the $2^{\text {nd }}$ moment is spectral width. Also available are the raw spectra files. Unlike the millimeter wavelength cloud radar (MMCR), the WACR does not use pulse coding and operates in only copolarization and cross-polarization modes.

\section{Contacts}

\subsection{Mentor}

Kevin Widener

Pacific Northwest National Laboratory

P.O. Box 999

Richland, WA 99952

Phone: 509-375-2487

Fax: 509-375-6736

kevin.widener@pnl.gov

Karen Johnson

Environmental Sciences Department

Brookhaven National Laboratory

Upton, NY 11973

Phone: 631-344-5952

Fax: 631-344-2060

kjohnson@bnl.gov

\subsection{Instrument Developer}

James Mead, President

ProSensing, Inc.

107 Sunderland Road

Amherst, MA 01002

Phone: 413-549-4402

mead@prosensing.com 


\section{Deployment Locations and History}

Table 1 displays the locations and status of each WACR.

\begin{tabular}{||c|c|c|c||}
\hline \multicolumn{4}{||}{ Table 1. WACR Deployment Locations and Dates } \\
\hline Location & Date Installed & Date Removed & Status \\
\hline SGP/C1 & $07 / 01 / 2005$ & & Operational \\
\hline AMF/M1 & $03 / 16 / 2006$ & & Operational \\
\hline
\end{tabular}

The first WACR was installed at the Southern Great Plains (SGP) site in the same shelter as the 35-GHz MMCR in July 2005. In early August, it was removed from operation due to a problem with the transmitter. Reinstallation occurred in December 2005. From late January until mid-March 2006, the unit was redeployed to the ARM Mobile Facility (AMF) site. A new WACR was installed at the SGP site in late March 2006. The AMF WACR was first installed at Niamey in mid-March 2006.

\section{Near-Real-Time Data Plots}

Near-real-time WACR data plots are available from the ARM DQHandS Plot Browser, at http://dq.arm.gov/plotbowser/.

\section{Data Description and Examples}

WACR moments data are available from the ARM Climate Research Facility (ACRF) Data Archive in data stream "wacr."

Table 2 indicates which data streams are available at each site and time period:

\begin{tabular}{||l|l|l||}
\hline \multicolumn{3}{||c|}{ Table 2. WACR Data Stream Availability } \\
\hline \multicolumn{1}{|c|}{ Site } & \multicolumn{1}{|c|}{ Data Stream } & \multicolumn{1}{c|}{ Date Range } \\
\hline SGP & sgpwacrC1.b1 & $2005.07 .01-2005.07 .19$ \\
& & $2005.12 .13-2006.01 .26$ \\
& & 2006.03 .24 - Present \\
\hline NIM & nimwacrM1.b1 & 2006.03 .16 - Present \\
\hline
\end{tabular}

WACR spectra data are also collected continuously at each site. Approximately 15 GB of raw spectra files are generated per day. Due to the large volume of data collected, the disks containing spectra files are mailed to the archive every few weeks so there is a delay in their availability.

WACR spectra data are not in stored in NetCDF format, but rather in binary data files. They consist of a header block, with general information such as pulse repetition frequency, number of range gates, number of fast Fourier transformation (FFT) points, etc. followed by data values collected at each time. At each time, there are system temperature measurements followed by the measured spectrum stored as an $m \mathrm{X} n$ array, where $m$ is the number of range gates and $n$ is the number of FFT points. Detailed information on reading the binary spectra data format is available by emailing Karen Johnson at kjohnson@bnl.gov. 


\subsection{Data File Contents}

\subsubsection{Primary Variables and Expected Uncertainty}

Table 3 shows the primary quantities measured by the WACR for the wacr data stream.

\begin{tabular}{|l|l|l|}
\hline \multicolumn{2}{|c|}{ Table 3. Primary Variables } & \multicolumn{1}{c|}{ wacr Data Stream } \\
\hline \multicolumn{1}{|c|}{ Variable } & \multicolumn{1}{|c|}{ Description } & Uncertainty \\
\hline Reflectivity & WACR Reflectivity (time, height), in dBZ & $0.5 \mathrm{~dB}$ \\
\hline MeanDopplerVelocity & WACR Mean Doppler Velocity (time, height), in m/s & $0.1 \mathrm{~m} / \mathrm{s}$ \\
\hline SpectralWidth & WACR Spectral Width (time, height), in $\mathrm{m} / \mathrm{s}$ & $0.1 \mathrm{~m} / \mathrm{s}$ \\
\hline
\end{tabular}

The overall uncertainties for the primary quantities measured are as follows:

- Measurement accuracy: $0.5 \mathrm{~dB}$ over receiver dynamic range

- Doppler resolution: less than $0.1 \mathrm{~m} / \mathrm{s}$.

\subsubsection{Definition of Uncertainty}

We define uncertainty as the range of probable maximum deviation of a measured value from the true value within a 95\% confidence interval. Given a bias (mean) error $B$ and uncorrelated random errors characterized by a variance $\sigma^{2}$, the root-mean-square error (RMSE) is defined as the vector sum of these,

$$
R M S E=\left(B^{2}+\sigma^{2}\right)^{1 / 2}
$$

( $B$ may be generalized to be the sum of the various contributors to the bias and $\sigma^{2}$ the sum of the variances of the contributors to the random errors). To determine the $95 \%$ confidence interval we use the Student's $t$ distribution: $t_{\mathrm{n} ; 0.025} \approx 2$, assuming the RMSE was computed for a reasonably large ensemble. Then the uncertainty is calculated as twice the RMSE.

\subsubsection{Secondary/Underlying Variables}

Table 4 presents the secondary variables measured by the WACR.

\begin{tabular}{||c|c||}
\hline \multicolumn{2}{|c|}{ Table 4. Secondary Variables } \\
\hline \multicolumn{2}{|c|}{ wacr Data Stream } \\
\hline Variable & Description \\
\hline Polarization & $0=\mathrm{copol} / 1=$ crosspol \\
\hline
\end{tabular}




\subsubsection{Diagnostic Variables}

Table 5 presents the diagnostic variables measured by the WACR.

\begin{tabular}{|c|c|}
\hline \multicolumn{2}{|c|}{ wacr Data Stream } \\
\hline $\begin{array}{r}\text { Variable } \\
\end{array}$ & Description \\
\hline PowerAmbientLoad & Ambient load power in $\mathrm{dBm}$ \\
\hline Power HotLoad & Hot load power in $\mathrm{dBm}$ \\
\hline PowerTransmitDriver & $\begin{array}{l}\text { Transmit driver power sampled by receiver in } \\
\mathrm{dBm}\end{array}$ \\
\hline txpower & Detected pulse (Watts) \\
\hline wacr_status & Status flag \\
\hline Temp_ambient & $\begin{array}{l}\text { Ambient temperature of radar front end } \\
\text { components (deg. C) }\end{array}$ \\
\hline Temp_LNA & Low noise amplifier temperature (deg. C) \\
\hline Temp_Hot & Hot load physical temperature (deg. C) \\
\hline Temp_EIKA & $\begin{array}{l}\text { Extended Interaction Klystron Amplifier } \\
\text { temperature (deg. C) }\end{array}$ \\
\hline Temp_modulator & Modulator temperature (deg. C) \\
\hline Temp_Chiller & $\begin{array}{l}\text { Chiller reservoir temperature (deg. C) } \\
\text { (SGP only) }\end{array}$ \\
\hline Temp_Antenna_Top & $\begin{array}{l}\text { Antenna top temperature (deg. C), } \\
\text { (AMF only) }\end{array}$ \\
\hline Temp_Antenna_Bottom & $\begin{array}{l}\text { Antenna bottom temperature (deg. C) } \\
\text { (AMF only) }\end{array}$ \\
\hline Temp_Modulator_Control & $\begin{array}{l}\text { Modulator control temperature (deg. C) } \\
\text { (AMF only) }\end{array}$ \\
\hline Temp_Future & For future use \\
\hline Temp_Outside & $\begin{array}{l}\text { Outside temperature (deg. C) } \\
\text { (AMF only) }\end{array}$ \\
\hline Temp_Computer_Enclosure & $\begin{array}{l}\text { Computer enclosure temperature (deg. C) } \\
\text { (AMF only) }\end{array}$ \\
\hline Temp_Chiller_Supply & $\begin{array}{l}\text { Chiller supply temperature (deg. C) } \\
\text { (AMF only) }\end{array}$ \\
\hline Temp_Chiller_Return & $\begin{array}{l}\text { Chiller return temperature (deg. C) } \\
\text { (AMF only) }\end{array}$ \\
\hline Noise & Calculated noise $(\mathrm{dB})$ \\
\hline
\end{tabular}

\subsubsection{Data Quality Flags}

There are three data quality flags in the wacr data stream:

qc_time: Contains the results of quality checks on sample time. This field has a value at each sample time. The qc_time values are calculated by comparing each sample time with the previous time. In the table below, Delta_time $=\mathrm{t}[\mathrm{n}]-\mathrm{t}[\mathrm{n}-1]$. 
qc_time:

$1=$ Delta_time is within expected interval

2 = Delta_time is zero: Duplicate sample times

4 = Delta_time is greater than expected

8 = Delta_time is less than expected.

qc_Reflectivity: Contains the results of quality checks on Reflectivity. This field has a value at each sample time and height. The qc_Reflectivity values are calculated by comparing Reflectivity values to reasonable maximum and minimum values. The value ' 0 ' indicates acceptable Reflectivity values.

qc_MeanDopplerVelocity: Contains the results of quality checks on MeanDopplerVelocity. This field has a value at each sample time and height. The qc_MeanDopplerVelocity values are calculated by comparing MeanDopplerVelocity values to reasonable maximum and minimum values. The value ' 0 ' indicates acceptable MeanDopplerVelocity values.

QC flag values for the above two flags can be interpreted as follows:

$0=$ Value is within the valid range

$1=$ value is missing

$2=$ value is less than the valid minimum

$4=$ value is greater than the valid maximum

8 = value failed the valid delta check, relative to previous value.

\subsubsection{Dimension Variables}

\begin{tabular}{||l|l||}
\hline \multicolumn{1}{||c||}{ Table 6. Dimension Variables } \\
\hline \multicolumn{1}{|c||}{ Variable } & \multicolumn{1}{c||}{ Description } \\
\hline alt & $\begin{array}{l}\text { Altitude, meters above mean sea level, of ground } \\
\text { instrument is sited on }\end{array}$ \\
\hline base_time & $\begin{array}{l}\text { Base time for file, in seconds since 1/1/1970 } \\
00: 00: 00 \text { GMT }\end{array}$ \\
\hline heights & $\begin{array}{l}\text { Range heights in meters above mean sea level of } \\
\text { data collection (center of radar sample volume) }\end{array}$ \\
\hline lat & North latitude in degrees \\
\hline lon & East longitude in degrees \\
\hline time & $\begin{array}{l}\text { Time offset in seconds from midnight on file's } \\
\text { collection date }\end{array}$ \\
\hline time_offset & Time offset in seconds from base_time \\
\hline
\end{tabular}

\section{Annotated Examples}

Below are example plots of copolarization moments (reflectivity, mean Doppler velocity, and spectral width) from the SGP WACR followed by plots of cross-polarization moments, both for 20060411. 

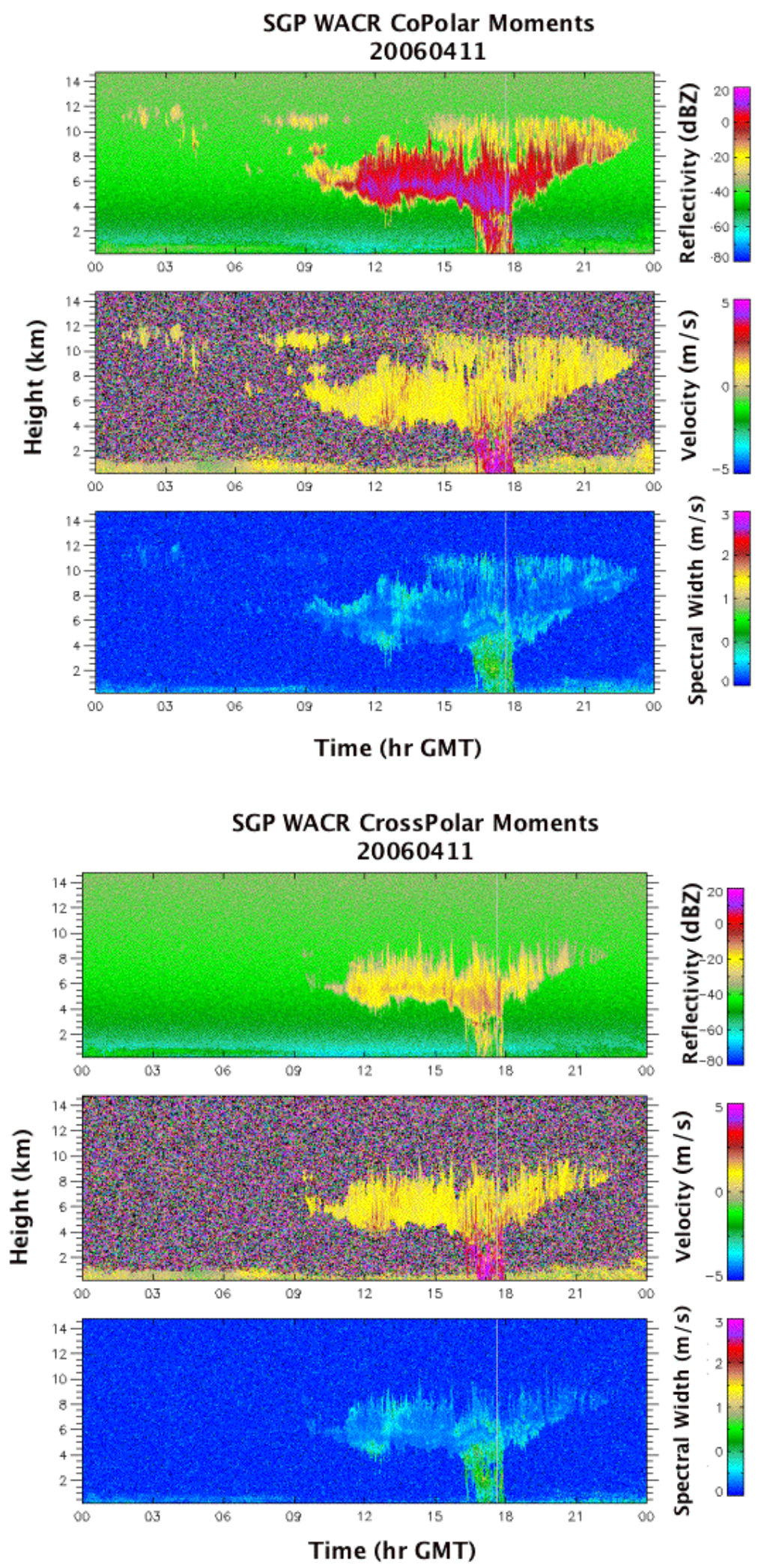

Figure 1. Plots of copolarization (top) and cross-polarization (bottom) moments, both for the SGP WACR. 
Next are plots from the AMF WACR at Niamey, first copolarization moments followed by crosspolarization moments for 2006402:
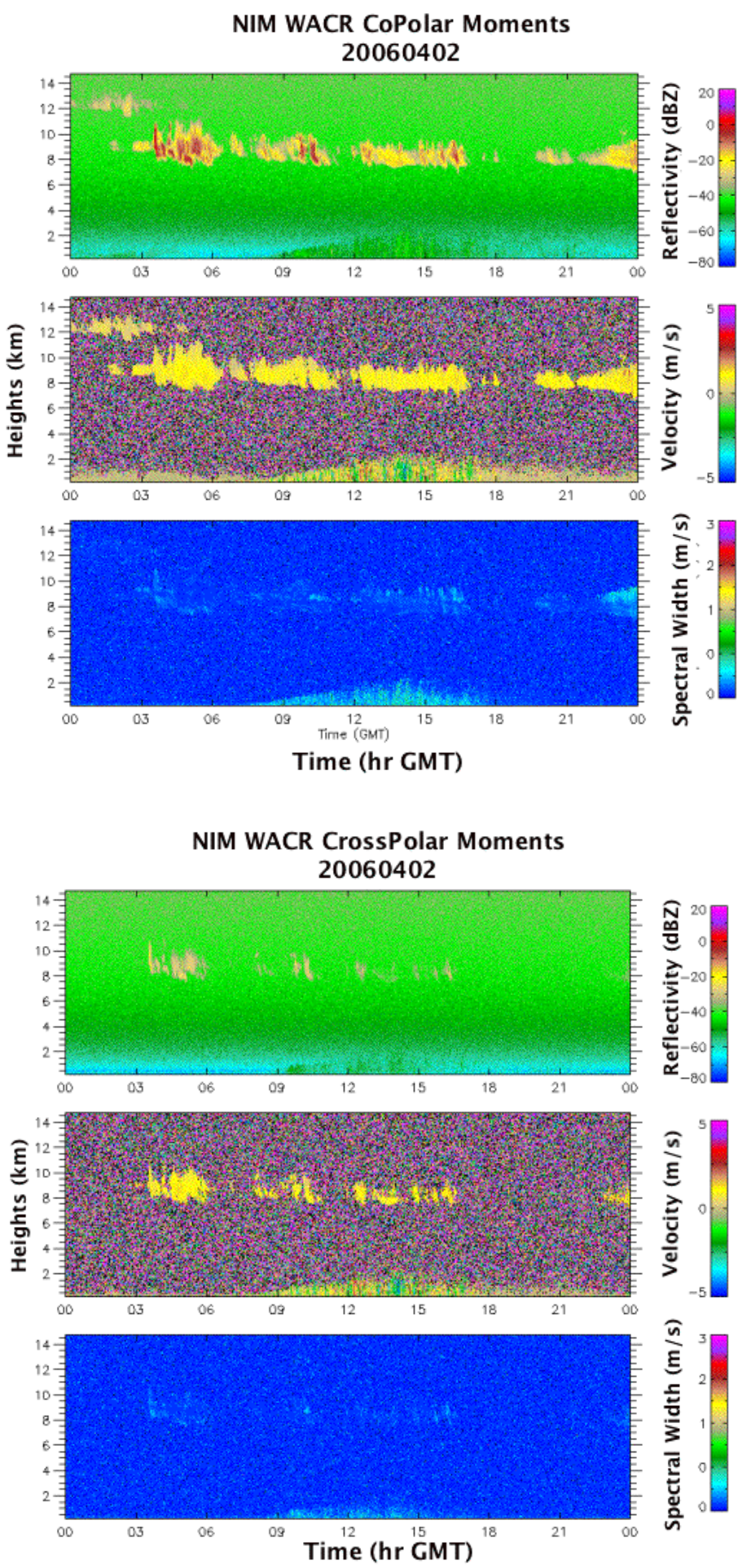

Figure 2. Plots of copolarization (top) and cross-polarization (bottom) moments from the AMF WACR at Niamey. 


\subsection{User Notes and Known Problems}

N/A

\subsection{Frequently Asked Questions}

What index of refraction for water is used to computer reflectivity (Kw) at $95 \mathrm{GHz}$ ?

0.84 at $95 \mathrm{GHz}$ vs. 0.93 for $35 \mathrm{GHz}$

\section{Data Quality}

\subsection{Data Quality Health and Status}

The Data Quality Office website has links to several tools for inspecting and assessing WACR data quality:

- $\quad$ DQ HandS (Data Quality Health and Status)

- DQ HandS Plot Browser

- NCVweb: Interactive web-based tool for viewing ARM data.

Plots of reflectivity, Doppler radial velocity, and Doppler spectral width provide a good indicator of whether the system is operational or not.

\subsection{Data Reviews by Instrument Mentor}

Data reviews are done weekly. Monthly assessments will be provided here in the future.

\subsection{Data Assessments by Site Scientist/Data Quality Office}

All Data Quality Office and most Site Scientist techniques for checking have been incorporated within DQ HandS and can be viewed there.

\subsection{Value-Added Products and Quality Measurement Experiments}

At present, no Value-Added Products or Quality Measurement Experiment exist for the WACR. 


\section{Instrument Details}

\subsection{Detailed Description}

\subsubsection{List of Components}

The following is a list of components for the WACR:

- CPI Extended Interaction Amplifier (EIKA)

- Pulse Technology modulator

- Antenna

- Radio Frequency Section

- Radar controller

- Radar computer

- Chiller

- Uninterruptible Power Supply.

\subsubsection{System Configuration and Measurement Methods}

The WACR system consists of the radar, data acquisition/control subsystem, enclosures, cables, and accessories so that it will be operable in a semi-autonomous mode. For the purposes of this specification, semi-autonomous operation is defined as a mode wherein an operator is required only to power up and power down the system. Once powered up, the WACR will automatically enter a standby mode ready to begin taking data.

\subsubsection{Specifications}

\section{Radar specifications are as follows:}

Frequency

Peak Transmitted Power

Maximum Duty Cycle

Antenna Diameter

Antenna Gain

Beam Width (full-width, half-maximum)

PRF (max)
$95 \mathrm{GHz}$ (Wavelength $3.16 \mathrm{~mm}$, W band)

$1500 \mathrm{~W}$

$0.1 \%$

SGP: $2 \mathrm{ft}$

AMF: $4 \mathrm{ft}$

see table under Calibration History

see table under Calibration History

$20 \mathrm{kHz}$

\section{WACR Mode Sequence and Characteristics}

The WACR alternates between copolarization and cross-polarization modes continuously. Table 7 gives operating characteristics at each site. 


\begin{tabular}{||l|c|c||}
\hline \multicolumn{1}{|c|}{ Table 7. WACR Operation Parameters } \\
\hline \multirow{2}{*}{ Radar Parameter } & SGP & AMF NIM \\
\cline { 2 - 3 } & 10000 & 10000 \\
\hline Pulse Repetition Frequency (Hz) & 0.3 & 0.3 \\
\hline Pulse Width (microsec) & 0.143 & 0.143 \\
\hline Gate Spacing (microsec) & 348 & 348 \\
\hline Number of Gates & 160 & 160 \\
\hline Spectral Averages & 256 & 256 \\
\hline FFT Length & 2.14 & 2.14 \\
\hline Obs. / Processing Time & 7.885 & 7.885 \\
\hline Nyquist Velocity (m/s) & \multicolumn{2}{c||}{} \\
\hline
\end{tabular}

\subsection{Theory of Operation}

The WACR works by transmitting a pulse of millimeter-wave energy from its transmitter through the antenna. The energy propogates through the atmosphere until it intercepts objects that reflect some of the energy back to the WACR. These objects can be clouds, precipitation, insects, spider webs, man-made objects, etc. The same antenna is used to receive the return signal. The received signal is downconverted into an intermediate frequency that is then fed to a digital receiver. A digital receiver processes the signal and ultimately provides the radar spectra. From the radar spectra, power, Doppler velocity, and spectral width are calculated. The power measurement is processed by knowing the WACR's calibration coefficient to provide the radar reflectivity.

Looking at the meteorological radar range equation gives insight as to how the WACR works and what parameters affect its sensitivity. Any radar's sensitivity is proportional to the transmit power, the square of the antenna gain, and the square of the radar's wavelength. The sensitivity is inversely proportional to the square of the range from the radar to the target.

\subsection{Calibration}

\subsubsection{Theory}

Several systems within the radar require calibration at regular intervals. The values obtained from these calibrations are stored as constants, polynomials, or curves in the calibration files or programs. These are used by the software to convert raw radar moment files to range-corrected power $(\mathrm{dBm})$ and reflectivity (dBZ) data in netCDF format and sent to the site data system.

\subsubsection{Procedures}

N/A

\subsubsection{History}

N/A 


\subsection{Operation and Maintenance}

N/A

\subsubsection{User Manual}

N/A

\subsubsection{Routine and Corrective Maintenance Documentation}

N/A

\subsubsection{Software Documentation}

N/A

\subsubsection{Additional Documentation}

N/A

\subsection{Glossary}

See the ARM Glossary.

\subsection{Acronyms}

$\begin{array}{ll}\text { AMF } & \text { ARM Mobile Facility } \\ \text { ARM } & \text { Atmospheric Radiation Measurement (Program) } \\ \text { EIKA } & \text { Extended Interaction Klystron Amplifier } \\ \text { FFT } & \text { fast Fourier transformation } \\ \text { Lidar } & \text { Light Detection and Ranging } \\ \text { MMCR } & \text { millimeter wave cloud radar } \\ \text { MMW } & \text { Millimeter wave (30GHz - 300GHz) } \\ \text { MPL } & \text { Micropulse LIDAR } \\ \text { NIM } & \text { Niamey, Niger } \\ \text { NOAA } & \text { National Oceanic and Atmospheric Administration } \\ \text { NSA } & \text { North Slope of Alaska } \\ \text { QC } & \text { quality control } \\ \text { RMSE } & \text { root-mean-square error } \\ \text { SGP } & \text { Southern Great Plains } \\ \text { TWP } & \text { Tropical Western Pacific } \\ \text { WACR } & \text { Wband ARM Cloud Radar }\end{array}$

Also, see ARM Acronyms and Abbreviations. 


\subsection{Bibliography}

Albrecht, BA, TP Ackerman, G Mace, DW Thomson, MA Miller, and RM Peters. 1991. "A surfacebased cloud observing system.” Preprint Volume, Seventh Conference on Meteorological Observations and Instrumentation, pp. 443-446, New Orleans, Louisiana.

Baum, BA, T Uttal, M Poellot, TP Ackerman, JM Alvarez, J Intrieri, D O’C. Starr, J Titlow, V Tovinkere, and EE Clothiaux. 1995. "Satellite remote sensing of multiple cloud layers.” Journal of Atmospheric Science 52:4210-4230.

Bogush, A. 1989. Radar and the Atmosphere, Artech House.

Clothiaux, EE, MA Miller, BA Albrecht, TA Ackerman, J Verlinde, DM Babb, RMPeters, and WJ Syrett. 1995. “An evaluation of a 94-GHz radar for remote sensing of cloud properties.” Journal of Atmospheric and Oceanic Technology 12:201-229.

Currie, N and C Brown. 1987. Principles and Applications of Millimeter-Wave Radar, Artech House.

Dong, X, TP Ackerman, EE Clothiaux, P Pilewskie, and Y Han. 1997. "Microphysical and radiative properties of boundary layer stratiform clouds deduced from ground-based measurements." Journal of Geophysical Research 102:23829-23843.

Doviak, RJ, and DS Zrni. 1993. "Doppler Radar and Weather Observations.” 2 ed., Academic Press, p. 562.

Frisch, AS, CW Fairall, and JB Snider. 1995. "Measurement of stratus cloud and drizzle parameters in ASTEX with a Ka-band doppler radar and microwave radiometer." Journal of Atmospheric Science 52:2788-2799.

Hobbs, PV, NT Funk, RR Weiss, JD Locatelli, and KR Biswas. 1985. "Evaluation of a 95- GHz radar for cloud physics research.” Journal of Atmospheric and Oceanic Technology 2:95-48.

Intrieri, JM, GL Stephens, W Eberhard, and T Uttal. 1993. “A method for determining cirrus cloud particle sizes using a lidar and radar backscatter technique.” Journal of Applied Meteorology 32:1074-1082.

Intrieri, JM, WL. Eberhard, T Uttal, JA Shaw, JB Snider, Y Han, BW Orr, and SY Matrosov. 1995. "Multiwavelength observations of a developing cloud system: the FIRE II 26 November 1991 case study.” Journal of Atmospheric Science 52:4079-4094.

Kropfli, RA and RD Kelly. 1996. "Meteorological research applications of a mm-wave radar.” Meteorological and Atmospheric Physics 59:105-121.

Lhermitte, RM. 1987. “A 94-GHz doppler radar for cloud observations.” Journal of Atmospheric and Oceanic Technology 4:36-48. 
Lhermitte, RM. 1987. "Small cumuli observed with a 3-mm wavelength doppler radar.” Geophysical Research Letters 14:707-710.

Lhermitte, RM. 1988. "Cloud and precipitation remote sensing at $94 \mathrm{GHz}$." IEEE Transactions of the Geosciences Remote Sensing 26:207-218.

Lhermitte, RM. 1990. "Attenuation and scattering of millimeter wavelength radiation by clouds and precipitation.” Journal of Atmospheric and Oceanic Technology 7:464-479.

Liebe, HJ. 1985. “An updated model for millimeter wave propagation in moist air.” Radio Science 20(5):1069-1089.

Liebe, HJ, T Manabe, and GA Hufford. 1989. "Millimeter-wave attenuation and delay rates due to fog/cloud conditions.” IEEE Transactions on Antennas Propagation 37(12):1617-1623.

Liebe, HJ. 1989. “MPM-An atmospheric millimeter-wave propagation model.” International Journal of Infrared and Millimeter Waves 10(6):631-650.

Mace, GG, DO’C. Starr, TP Ackerman, and P Minnis. 1995. “Examination of coupling between an upper-tropospheric cloud system and synoptic-scale dynamics diagnosed from wind profiler and radiosonde data.” Journal of Atmospheric Sciences 52:4094-4127.

Martner, BE and RA Kropfli. 1993. “Observations of multi-layered clouds using Ka-band radar.” In Proceedings of the Thirty-first Aerospace Science Meeting, AIAA, p. 8, Washington, D.C.

Matrosov, SY, T Uttal, JB Snider, and RA Kropfli. 1992. "Estimation of ice cloud parameters from ground-based infrared radiometer and radar measurements.” Journal of Geophysical Research 97:11567-11574.

Matrosov, SY. 1993. "Possibilities of cirrus particle sizing from dual-frequency radar measurements.” Journal of Geophysical Research 98, 20675-20683.

Matrosov, SY, AJ Heymsfield, JM Intrieri, BW Orr, and JB Snider. 1995. “Ground-based remote sensing of cloud particle sizes during the 26 November 1991 FIRE II cirrus case: comparisons with in situ data.” Journal of Atmospheric Science 52:4128-4142.

Mead, JB, RE McIntosh, D Vandemark, and CT Swift. 1989. "Remote sensing of clouds and fog with a 1.4-mm radar.” Journal of Atmospheric and Oceanic Technology 6:1090-1097.

Miller, MA, MP Jensen, and EE Clothiaux. 1998. "Diurnal variability in the stratocumulus transition region: a case study using 94 GHz radar.” Journal of Atmospheric Science 55:2294-2310.

Miller, MA and BA Albrecht. 1995. "Surface-based observations of cumulus-stratocumulus interaction during ASTEX.” Journal of Atmospheric Science 52:2809-2826. 
Moran, KP, BE Martner, DC Welsh, DA Merritt, MJ Post, and T Uttal. 1997. “ARM's cloud-profiling radar. In Proceedings of the Twenty-eighth Conference on Radar Meteorology, Austin, Texas.

Pasqualucci, F, BW Bartrum, RA Kropfli, and WR Moninger. 1983. “A millimeter-wavelength dualpolarization doppler radar for cloud and precipitation studies.” Journal of Climate and Applied Meteorology 22:758-765.

Peters, RM, BA Albrecht, MA Miller, and JT Treaster. 1992. “Automated cloud profiling with a $94 \mathrm{GHz}$ radar." In Proceedings of the Eleventh International Conference on Clouds and Precipitation, Montreal, Quebec, Canada. August 17-21, 1992.

Planck, VG, D Atlas, and WH Paulsen. 1955. "The nature and detectability of clouds and precipitation as determined by a 1.25 centimeter radar.” Journal of Meteorology 12:958-378.

Post, MJ, KP Moran, and B Martner. 1996. Contractors for the Department of Energy ARM Program Millimeter-Wave Radars. Environmental Technology Laboratory, ERL, NOAA.

Probert-Jones, JR. 1962. “The radar equation in meteorology.” Quarterly Journal of the Royal Meteorological Society 88:485- 495.

Saugageot, H. 1992. Radar Meteorology, Artech House.

Sekelsky, SM, and RE McIntosh. 1996. "Cloud Observations with a Polarimetric $33 \mathrm{GHz}$ and $95 \mathrm{GHz}$ Radar.” Meteorological and Atmospheric Physics 59:123-140.

Skolnik, M. 1990. Radar Handbook, Merril Skolnik, McGraw-Hill.

Uttal, T, JM Intrieri, WL Eberhard, TP Ackerman, and EE Clothiaux. 1995. "Cloud boundaries during FIRE II.” Journal of Atmospheric Sciences 52:4276-4284.

Wexler, R and D Atlas. 1959. “Precipitation generating cells.” Journal of Meteorology 16:327-332. 